\title{
Relationship between Suicidal Thoughts and Positive Symptoms among Schizophrenic Patients
}

\author{
Basma Elsayed Ahmed ${ }^{1}$, Maaly Ibrahim Elmaleky ${ }^{2}$ and Mawaheb Mahmoud Zaki ${ }^{3}$
}

(1) Nursing Specialist at Benha Fever Hospital, Egypt, (2) Professor of Psychiatric and Mental Health Nursing, Faculty of Nursing, El Menoufia University, Egypt. (3) Assistant Professor of Psychiatric and Mental Health Nursing, Faculty of Nursing, Benha University, Egypt

\begin{abstract}
Background: Suicide behavior is a serious public health problem among schizophrenic patients and need for medication and psychotherapy for prevention. Aim: This study aimed to assess the relationship between suicidal thoughts and positive symptoms among schizophrenic patients. Design: Descriptive correlational design was utilized to achieve the aim of the study. Setting: This study was conducted at Psychiatric and Mental Health Hospital in Banha city. Subjects: Sample size was 100 schizophrenic patients were included in the study. Tools of data collection: Three tools were used to collect data. I: A structured interview questionnaire to assess socio-demographic data and clinical data. II: Scale for assessment of positive symptoms and III: Beck scale for suicide ideation. Results: More than three quarters of the studied patients have severed level of positive symptoms. Majority of the studied subject expressed that they have moderate to strong wish to die, moderate to strong active suicide attempt and the Frequency of suicide ideation are persistent or continuous respectively. Majority of the studied subject respectively expressed that they are accepting their attitude toward the ideation and have no sense of control over suicidal action Conclusion: There was highly positive significant correlation between total scale for the assessment of positive symptoms and total suicidal thought. Recommendation: The development of psychological interventions, Family interventions may reduce the risk of suicidal behavior and further studies are necessary using a large probability sample for generalization of the results.
\end{abstract}

\section{Keywords: Positive Symptoms - Schizophrenic Patients - Suicidal Thoughts. \\ Introduction \\ psychiatric disorder characterized by continuous or relapsing episodes of psychosis}

Schizophrenia is a mental illness that is characterized by disturbances in thought (as delusions), perception (as hallucinations), and behavior (as disorganized speech or catatonic behavior), by a loss of emotional responsiveness and extreme apathy, and by noticeable deterioration in the level of functioning in everyday life. Or Schizophrenia is a chronic, severe mental disorder that affects the way a person thinks, acts, expresses emotions, perceives reality, and relates to others. Schizophrenia is a (Owen et al., 2016).

People with schizophrenia often have problems doing well in society, at work, at school, and in relationships. They might feel frightened and withdrawn, and could appear to have lost touch with reality. This lifelong disease can't be cured but can be controlled with proper treatment. This means that person has difficulty in thinking clearly, knowing what real, managing feelings are, making decisions and relating to other (National Institute of Mental Health, 2020)

\section{JNSBU}


The specific causes of schizophrenia are not known and combinations of several factors are likely to be involved. Genetic factors play a major role in the development of the disease, and environmental factors are also of importance. These latter factors include a history of obstetric complications, such as asphyxia and prematurity. Advanced paternal age is also considered to be a risk factor, and birth during the spring and late winter also increases the risk. Prenatal viral infections, serious viral infections of the CNS during childhood, migrant status and urban rearing, and a lifetime history of cannabis use are other well-known risk factors (Javitt, 2019).

Suicide is an intension or act of deliberately ending one's own life, and suicide behavior is a feeling or intention that increases a person's risk of attempting or committing suicide, which may include suicidal thoughts or wishes, suicidal plans, and suicidal attempts. Suicide is a highly prevalent and significant public health problem resulting in nearly a million deaths per year. Suicide is responsible for enormous distress to individuals, families, friends, and community (National Institute of Mental Health, 2021).

Suicide behavior in patients with schizophrenia is often due to the momentous psychosocial and economic burden on individuals and families. Patients with schizophrenia die much earlier than expected, and up to $40 \%$ of these premature deaths can be due to suicide. Studies estimated that nearly half $(50 \%)$ of PWS attempt suicide, and around $10 \%$ completed suicide during their lifetime. Epidemiological investigations indicated that PWS have about eight times increased risk of suicide than the general population due to the complex and challenging nature of the symptoms of the disorder. During the course of the illness, $40 \%$ to $80 \%$ of PWS had suicidal ideation. Suicidal ideations are very common in first psychotic episode (World Health Organization, 2021).

Suicide attempts occur in $20 \%$ to $50 \%$ of individuals having suicidal ideation, and $4 \%$ to $13 \%$ of them die from suicide. In a retrospective medical record review of patients with schizophrenia, found out that about half $(52 \%)$ and $28 \%$ had suicidal behavior (both suicidal thought and attempt) and attempted suicide at least once during the course of the disease, respectively. Most suicide behaviors for PWS occur within the first ten years, and $50 \%$ happen in the first two years after onset of the illness. Also, the risk of committing suicide is high in the first weeks or months after discharge from the hospital. In one follow-up study, $80 \%$ of PWS committed suicide while they were in hospital or in the first six months after discharge from hospital, and this may be as a result of "post psychotic depression (Leo \& René, 2019).

The nursing assessment of the person with schizophrenia is a complex process in most cases, requiring the collection of data from several sources, since in the acute phase of the disease the person is rarely able to give reliable information. It is necessary to appeal to the family and significant people, as well as to clinical records when they exist. Initially a mental examination should be performed, identifying the present symptomatology, such as delusions, hallucinations, disorganization and negative symptomatology. In order for an adequate evaluation to be performed, the nurse must know the characteristic behaviors of this disorder (Eed \&El-sayed, 2018). 


\section{Significance of the study:}

Schizophrenia is a debilitating mental disorder characterized by distorted thinking despite advances in the treatment of psychiatric diseases in recent decade's suicide is still a major health problem, with approximately 1 million cases per year and an enormous social and economic burden worldwide. The mortality gap between the general population and patients with schizophrenia turns the focus not only to the treatment of the psychiatric disorder itself, but also to somatic diseases and general health interventions with population strategies. Suicide is a major challenge among patients with schizophrenia and, because of the complexity of suicidal behavior; it has become increasingly clear that an integrated approach is needed to attack the problem.

\section{Aim of the study}

The aim of this study was to assess the relationship between suicidal thoughts and positive symptoms among schizophrenic patients.

\section{Research Questions:}

1) What are the relationship between suicidal thoughts and positive symptoms among schizophrenic patients?

\section{Subject and Methods:}

\section{Research Design:}

Descriptive correlational design was utilized to achieve the aim of the study

\section{Research Setting:}

This study was conducted at The Psychiatric and Mental Health Hospital in Banha city, which is affiliated to the General Secretariat it has $\{(6)$ departments (4) males , (1) female and (1) addiction department\}, with capacity of 219 beds. This hospital provides care for patients diagnosed with acute and chronic mental illness that needs institutional care.

\section{Sample:}

Sampling technique:

Selection of the sample contained sample type, sample size and criteria for inclusion.

\section{Sample type:}

A convenience sample of schizophrenic patients to conducting this study

\section{Sample size:}

100 schizophrenic patients according to inclusion criteria were included for the conduction of this study (69) male and (31) female.

\section{Inclusion criteria}

- Schizophrenic patients age between 2565years.

- Free from another psychiatric disorders

- Able to communicate

- Agreed to participate in the study

\section{Tools for Data Collection:}

In order to fulfill the objective of the study, the data collected was using the following tools:

\section{Tool (I): A structured Interview Questionnaire:}

This tool developed by the researcher that composed of two parts:

Part (1): Socio-demographic Data: Such as (gender, age, marital status,).

Part (2): Clinical Data: Which include age of onset of the disease, duration of illness, entry method.

Tool (II): The Scale for the Assessment of Positive Symptoms (SAPS)

It is rating scale to measure positive symptoms in schizophrenia. The scale was developed by (Andresen et.al.1991) and was first published in 1984. SAPS is split into 4 domains, (1) Hallucination consist of 6 items, (2) Delusion consist of 12 items, (3) Bizarre Behavior consist of 4 items, (4) Positive formal Thought disorder consist of 8 items 
and within each item in domain separate symptoms are rated from 0 (absent) to 5 (severe).

The scoring system consists of $\mathrm{No}=0$, sometimes $=1$, usually $=2$, always $=3$.

Reliability of the Scale for the Assessment of Positive Symptoms Scale $=0.87$

\section{Tool (III): Beck Scale for Suicide Ideation} (BSS) (Tyrer et al., 2006).

It was developed by Aaron Beck and was first published in 1991and it used to attitudes and behaviors that clinicians routinely consider when assessing a patient's suicide risk. The BSS contains 19 statement groups each assessing various aspects of suicidal ideation. Each statement group consists of three sentences that describe different intensities of suicidal ideation, representing a three-point scale from (zero to 2). Participants are instructed to choose the particular statement of each group that is most applicable to them.

The total BSS score can range from zero to 38 , with higher values indicating a greater risk of suicide.

Reliability Beck Scale for Suicide Ideation scale $=0.77$

\section{Tools Validity \& Reliability}

Two types of validity tests were used at this stage: Face and content validity. Face validity aimed at inspection the items to determine whether the tools measure what is supposed to measure. Content validity was conducted to determine whether the tools cover the appropriate and necessary content as well as its relevance to the tools and the study aim. Face and content validity of tools were done by a jury of five experts of Psychiatry Mental Health Nursing and Public Health Nursing. Internal consistency of the tools was checked by test retest reliability. Tools were strongly reliable at (0.93) for SAPS and at (0.89) for BSS.

\section{Pilot study:}

After the tool have been designed, they were tested through a pilot study, which was before embarking on the field work to check the clarity and feasibility of a designed tool to be sure that it was understood and to estimate the time needed to complete its items. It was carried out on a sample of 10schizophrenic patients, which were excluded from the main sample. After its implementation and according to its result, the necessary modifications were done under guidance of supervisors.

\section{Ethical considerations:}

Before conducting the study, all subjects informed that participation in the study is voluntary. Subjects were assured that the data collected from the questionnaires will remain confidential and that no personal identification was needed by any means. Subjects were informed that the content of the tool will be used for research purpose only and they could refuse to participate in the study or withdrawal from it at any time.

\section{Field work (Data collection):}

Once the official permissions were obtained from the principal person, and the other authorized personnel from the various settings, the researcher started the data collection at October 2020. The researcher started data collection by introducing herself to each participant. Then a brief description of the purpose of the study and the type of questionnaire required to fill was given to each participant. The confidentiality of any obtained information was assured, and the participants were informed about their right to participate or not in the study or withdrawal from it at any time. Data collected were done through interviewing with the schizophrenic patients in The Psychiatric and Mental Health Hospital in Banha city, which is affiliated to 
the General Secretariat. The researcher collected the data from the patients in the Morning shift 8 AM. To 2 PM. in the departments, Three days in a week; three hours per day, nearly from (9 to 10 patient) per week.Each interview lasted nearly one an hour for each patient, for Two months and half.Data were collected throughout the period of October 2020 to the middle of December 2020.

\section{Statistical analysis:}

Data entry and statistical analysis were done using the Statistical Package for Social Sciences (SPSS version 20) data were presented using descriptive statistics in form of number and percentages, mean, stander deviation. Qualitative variables were compared using the chi-square test and correlation coefficient was used to measure the direction and strength of the correlation between variables.

\section{Results}

Table (1): Describes the characteristics of the studied schizophrenic patients. It indicates that near of three quarters of the studied sample $(69.0 \%)$ are male .less than half of them $(46.0 \%)$ are at age group ranged between $36<46$ years with mean $43.28 \pm$ 8.48. Also more than half of them are single $(63.0 \%)$. More than half $(62.0 \%)$ of them a $\mathrm{r}$ e from moderate social class. More than half of the studied samples are in Secondary Education (51.0\%). More than half $(64.0 \%)$ are occupied and more than half of them $(58.0 \%)$ are living in rural.

Table (2): Illustrates that, near to three quarters of the studied schizophrenic patients $(68.0 \%)$ their age are ranged between $16<25$ years at onset of schizophrenia. More than half of them $(51.0 \%)$ the period of their illness are ranged between $1<10$ years. Majority of the studied sample $(92.0 \%)$ are mandatory entry. More than quarters of them, (26.0\%) are abusing alcohol, drugs, or narcotic substances and near to three quarters of them $(68.0 \%)$ are smoking.

Table (3): Illustrated that, there is positive significant correlation between age and both total SPAS and total suicidal thought. Also there is positive significant correlation between duration of disease and both total SPAS and total suicidal thought.

Table (4): illustrated that, there was highly positive significant correlation at $\mathrm{P}$-value $=(<$ $\left.0.001^{* *}\right)$ between total SAPS and total suicidal thought. 
Table (1): Frequency distribution of socio-demographic characteristics among studied schizophrenic patients $(n=100)$.

\begin{tabular}{|c|c|c|}
\hline Socio-demographic characteristics & No & $\%$ \\
\hline \multicolumn{3}{|l|}{ Gender } \\
\hline Female & 31 & 31.0 \\
\hline Male & 69 & 69.0 \\
\hline \multicolumn{3}{|l|}{ Age in years } \\
\hline $25-<36$ & 18 & 18.0 \\
\hline $36-<46$ & 46 & 46.0 \\
\hline $46-<56$ & 27 & 27.0 \\
\hline $56-\leq 65$ & 9 & 9.0 \\
\hline \multicolumn{3}{|l|}{ Min - Max } \\
\hline \multicolumn{3}{|c|}{$43.28 \pm 8.48$} \\
\hline \multicolumn{3}{|l|}{ Marital status } \\
\hline Single & 63 & 63.0 \\
\hline Married & 24 & 24.0 \\
\hline Widow & 2 & 2.0 \\
\hline Divorced & 11 & 11.0 \\
\hline \multicolumn{3}{|l|}{ Social class } \\
\hline Low & 28 & 28.0 \\
\hline Moderate & 62 & 62.0 \\
\hline High & 10 & 10.0 \\
\hline \multicolumn{3}{|l|}{ Education level } \\
\hline Illiterate & 8 & 8.0 \\
\hline Read And Write & 5 & 5.0 \\
\hline Basic & 18 & 18.0 \\
\hline Secondary & 51 & 51.0 \\
\hline University & 17 & 17.0 \\
\hline Post Graduate & 1 & 1.0 \\
\hline \multicolumn{3}{|l|}{ Occupation } \\
\hline Don't Work & 26 & 26.0 \\
\hline House Wife & 9 & 9.0 \\
\hline Work & 64 & 64.0 \\
\hline Student & 1 & 1.0 \\
\hline \multicolumn{3}{|l|}{ Residence } \\
\hline Rural & 58 & 58.0 \\
\hline Urban & 42 & 42.0 \\
\hline
\end{tabular}


Table (2): Frequency distribution of the clinical data among the studied patients $(n=100)$.

\begin{tabular}{|c|c|c|}
\hline Clinical Data & No & $\%$ \\
\hline \multicolumn{3}{|l|}{ Age at The Onset of The Disease } \\
\hline Less Than 16 Years & 1 & 1.0 \\
\hline $16-<25$ Years & 68 & 68.0 \\
\hline $25-<35$ Years & 24 & 24.0 \\
\hline $35-\leq 45$ Years & 4 & 4.0 \\
\hline More Than 45 Years & 3 & 3.0 \\
\hline \multicolumn{3}{|l|}{ Duration of The Illness } \\
\hline From 1 To 10 Years & 51 & 51.0 \\
\hline More Than 10 Years & 49 & 49.0 \\
\hline \multicolumn{3}{|l|}{ Entry Method } \\
\hline Mandatory & 92 & 92.0 \\
\hline Optional & 8 & 8.0 \\
\hline \multicolumn{3}{|c|}{ Abusing alcohol, drugs, or narcotic substances } \\
\hline No & 74 & 74.0 \\
\hline Yes & 26 & 26.0 \\
\hline \multicolumn{3}{|l|}{ Smoking } \\
\hline No & 32 & 32.0 \\
\hline Yes & 68 & 68.0 \\
\hline
\end{tabular}

Table (3): correlation between total SPAS and total suicidal thought among studied patient with their age and their duration of disease

\begin{tabular}{|c|c|c|c|}
\hline \multicolumn{2}{|c|}{ Items } & Total SPAS & Total suicidal thought \\
\hline \multirow{2}{*}{ Age } & $\mathbf{r}$ & 0.583 & 0.842 \\
\hline & p-value & $0.006^{*}$ & $0.020^{*}$ \\
\hline \multirow{2}{*}{$\begin{array}{l}\text { Duration of } \\
\text { disease }\end{array}$} & $\overline{\mathbf{r}}$ & 0.629 & 0.532 \\
\hline & p-value & $\overline{0.009 *}$ & 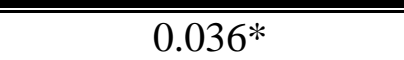 \\
\hline
\end{tabular}

Table (4): correlation between total SAPS and total suicidal thought

\begin{tabular}{|c|c|c||}
\hline \multicolumn{1}{|c|}{ Items } & \multicolumn{2}{|c|}{ Total SPAS } \\
\hline \hline \multirow{2}{*}{ Total Suicidal Thought } & $\mathrm{r}$ & $\mathrm{p}$-value \\
\cline { 2 - 3 } & 0.645 & $0.000^{* *}$ \\
\hline
\end{tabular}




\section{Discussion}

Schizophrenia is a serious mental health condition that causes disordered ideas, beliefs and experiences. In a sense, people with schizophrenia lose touch with reality and do not know which thoughts and experiences are real and which are not. Schizophrenia develops in about 1 in 100 people. It can occur in men and in women (Willacy. 2020). This study aimed to investigate relationship between suicidal thoughts and positive symptoms among schizophrenic patients.

Regarding Socio-demographic characteristics of the studied schizophrenic patients the present study finding showed that, near of three quarters of the studied schizophrenic patients were male, In relation to sex. From the researcher point of view it could be due to that the hospital have 4 departments for men and 1 department for females and it is fact about schizophrenia it more common in males than females .This result was consistent with the finding of the study by Willacy (2020) who clarified that male is relatively more common as main schizophrenic patients.

The present study revealed that near than half of the studied schizophrenic patients their age group of $36<46$ years with mean age Mean \pm SD $43.28 \pm 8.48$. From the researcher point of view it could be due to stressful life events at this age. This finding was consistent with the study by Albitar et al., (2021) who stated that more than half of them their age are between $35<45$ years with a mean age of $33.437 \pm 8.001$ years. While contradicted with the study done by Arafa et al., (2017) who found that more than one third of the studied patients their age ranged from 20to less than 30years. This contradiction could be due to schizophrenia disease typically emerges in late adolescence.

Regarding marital status, the current study noted that the majority of schizophrenia patients studied was single. From the researcher point of view it could be due to the schizophrenic patient may experience difficulties in social relationship led to reduce opportunities for marriage. This result was consistent with a study done by Pinho et al. (2020): The psychological resilience of schizophrenia patients studied who found that the majority of schizophrenia patients studied were single, while contradicted with the study done by Yazici et al., (2018) which reported that more than three quarters of studied schizophrenia patients are married. This contradiction could be due to cultural difference of the studied sample.

Concerning to the educational level, the present study revealed that more than half of the studied schizophrenia patients had diploma secondary school. From the researcher point of view it could be due to schizophrenic person suffers from deterioration in many aspects of his life, and he is cut off from study, his relationships with others worsen, and he is indifferent to important situations in his life. the result come in consistent with a study done by filipcic et al.,(2020) \& shalanda et al.,(2019) Who found that less than half of the studied patients had secondary education .while the result was contradicted with a study done by yttri et al.,(2020)who reported that ,less than half of the studied patients were illiterate, and contraindicated with the study by Sánchez et al., (2020) who stated that the highest percentages of participants were University. Meanwhile, one fifth of them were University and one third of study sample were Secondary. This contradiction could be due to the cognitive and symptomatic impairments that interfered with their ability for learning.

Regarding the occupation of the studied schizophrenia patients, the present study demonstrated that about two thirds of the studied schizophrenia patients were working. 
From the researcher point of view it could be due to symptoms stability of residual phase. This finding was consistent with the study by Cates et al., (2021) who stated that the majority of them were worked. While it contraindicated with a study by Manea et al., (2020) \& El-Monsheda \&Amr,(2020)who founded that, more than two thirds were unemployed. This contradiction could be due to schizophrenia cause profound disturbance in all aspects of daily life and occupational.

Regarding the nature of residence, the current study conducted that more than half of the schizophrenic patients lived in rural areas. From the researcher point of view it could be due to that such areas had low socioeconomic status of the individuals is a risk factor of incidence of schizophrenia and such type of mental illness attributed to a demonic possession or magic which in resulting poor prognosis in rural areas. The findings of the present study were in consistent with the study of Luo et al., (2020) \&McNamara et al., (2018) who found that more than half live in rural area. While it contraindicated with a study done by Manea et al.,(2020); \& setiawati \& suaryan,(2020)who found that the majority of the patients with schizophrenia were lived in urban area. This contradiction could be due to Lack of relaxation strategies due to noise pollution.

Concerning to clinical data of the studied schizophrenic patients, the present study revealed that near to three quarters of the studied schizophrenic patients were ranged between $16<25$ years at onset of schizophrenia. From the researcher point of view this could be due to the nature of the illness in its appearance between late adolescences and early adulthood. This finding were in consistent with the study by Dai et al., (2021) who stated that more than half of them their age are between $15 \leq 25$ years. While this study in contraindicated with a study done by Holm et al., (2020) that found that more than half of the studied patients were $\geq 35$ years. This contradiction could be due to the increase of responsibilities and stressors in this period.

In relation to period of illness the present study showed that semi half of the studied schizophrenic patients were less than ten years for the period of illness. From the researcher point of view this could be due to schizophrenia always tending to chronicity. This result is consistent with a study by Laura et al., (2021) who reported that more than half of the studied patients hospitalized less than 10 years. While this result was contraindicated with the finding of the study by Fekih-Romdhane et al., (2021)\& Mikhael et al.,(2020), who clarified that more than half of the studied schizophrenic patients were more than 20 years for the period of illness. This contradiction could be due to the differences between characterizes of the studied samples.

Regarding to entry method, the present study noticed that the majority of the studied schizophrenic patients were mandatory. From researcher point of view this could be due to lack of the patient insight regarding his illness and refusing hospitalization because of stigma of mental illness. This result was consistent with the study by Kiwan et al., (2020) who stated that more than three quarters of the schizophrenic patients were mandatory. The result of this study is contradicted with a study done by Ibrahim \& Ahmed, (2019) who found that only one third of the studied patients admitted involuntary. This contradiction could be due to there are patient have insight and know that in hospital they can have suitable care.

In relation to the patient is abusing alcohol, drugs, or narcotic substances, the present study showed that about one quarters of them were abusing alcohol, drugs, or 
narcotic substances. From the researcher point of view this could be due to the desired effects of alcohol use, occur because alcohol is a central nervous system depressant. This can be a great relief to someone with schizophrenia, as it dulls their senses and can make them less aware of what they are experiencing. This finding is in consistent with the study of Hassan et al., (2021) who stated that more than one-third of the studied schizophrenic patients were abusing alcohol, drugs, or narcotic substances.

Concerning to Smoking, the present study showed that near to three quarters of them were smoked. From the researcher point of view this could be due to the smoking has long been associated with impaired brain function, but schizophrenic patients have often been thought to be more likely to smoke because they use cigarettes as a form of selfmedication to relieve the distress of hearing voices or having hallucinations. The result is consistent with the study by Mikhael et al., (2020) who stated that the majority of schizophrenic patients were smoked.

The findings of the present study illustrated that, there is positive significant correlation between age and both total SPAS and total suicidal thought. Also there is positive significant correlation between duration of disease and both total SPAS and total suicidal thought. From the researcher point of view this could be due to worrying about his back to home and separation from family, often leading to hopelessness, depression, and anxiety. Furthermore, the lack of information on the health care's system, loss of status, loss of social network.

The findings of the present study were emphasized by Bornheimer et al., (2021) in a study in USA, entitled " Relationships between hallucinations, delusions, depression, suicide ideation, and plan among adults presenting with psychosis in psychiatric emergency care". The findings of the current study also came in the same line with the study of Ventriglio et al., (2016) who founded in his study that there was positive significant correlation between duration of disease and suicidal thought.

The present study results indicated that, the majority of the studied patients have severe suicide thought. From the researcher point of view this could be due to schizophrenic symptoms as auditory and visual hallucinations, which are thoughts that dominate the mind and isolate the owner from the outside world, and may push him under the pressure of life to commit suicide. Other societal causes that may lead to suicide, such as family disintegration, emptiness, loneliness, failure to take aim in life, fear of punishment, exposure to oppression and bullying. There are also economic conditions, such as poverty and unemployment; it may drive some people to suicide, as well as weak religious motives. Wrong handling of psychiatric medications and antidepressants may be among the reasons that may lead the owner to commit suicide.

This was supported by Stip et al., (2017) who found that the importance of the contribution of the variables of perceived cognitive dysfunction and stigmatization in the onset of suicidal ideation in people with schizophrenia spectrum disorders. The findings of the current study also came in the same line with the study of Paschall, (2021) found that there is sufficient evidence to suggest a link between suicide and positive symptoms among individuals with schizophrenia that depends on gender and racial and ethnic minority group membership.

The findings of the current study illustrated that there was highly positive correlation between total SAPS and total suicidal thought. From the researcher point of view this may be due to positive symptoms 
are likely to cause patients increased amounts of stress and anxiety, especially in the early stages of schizophrenia. Additionally, positive symptoms are more closely associated with suicidal ideations and completed suicides, as patients attempt to rid themselves of positive symptoms.

The findings were emphasized by Jahn et al., (2016), in the United States entitled "The interactive effects of negative symptoms and social role functioning on suicide ideation in individuals with schizophrenia". The findings of the current study also came in line with the study of Mondal \& Kumar (2021) entitled "Rorschach inkblot test and psychopathology among patients suffering from schizophrenia".

\section{Conclusion:}

More than three quarters of the studied patients have severe level of positive symptoms regarding their total SPAS and the majority of the studied patients have severe suicidal thought. There was highly positive significant correlation between total SAPS and total suicidal thought.

\section{Recommendations:}

The development of psychological interventions, inclusion of biological suicide research, involving neurochemical and genetic phenotypes, development of effective medical treatment and improvement of clinical risk markers of suicide are all important areas of research in the near future. It is importance that the development of evidence-based interventions to prevent suicidal behavior is transferred into the clinical setting and used by those working with patients at risk. Family interventions may reduce the risk of suicidal behavior, and therefore, should be a necessary component of a treatment plan of each patient with schizophrenia Families of individuals with schizophrenia need to be informed regarding manifestations of suicidality and what needs to be done if an individual with schizophrenia develops suicidal ideation, intent, or plan. Empirically based intervention programs focusing on well-known risk factors, especially for individuals with risk behaviors such as a history of attempted suicide, as well as appropriate use of antipsychotic medication, might help to reduce the mortality and suicide rate. Future studies may combine these risk factors with machine learning techniques in order to objectively predict at an individual level suicide and suicide attempt in patients with schizophrenia.

\section{References:}

Andresen N., Flaum M., Arndt S., Alliger Swayze V. (1991). Positive and negative symptoms: Assessment and validity. Negative vs Positive Schizophrenia.

Albitar, O., Harun, S., Ahmad, S. \& Ghadzi, S. (2021). A Repeated Time-toPositive Symptoms Improvement among Malaysian Patients with Schizophrenia Spectrum Disorders Treated with Clozapine. Pharmaceutics 2021, 13, 1121.

Arafa, H., Elmalky, M. \& Zaki, M. (2017). Relationship Between Positive Symptoms of Schizophrenia And Level of Anxiety Among Schizophrenic Patients, MNJ Menoufia Nursing Journal, Vol. 2, No. 2, Nov 2017, PP: 17-26

Bornheimer, L., Hong, V., Verdugo, J., Fernandez, L. \& King, C. (2021). Relationships between hallucinations, delusions, depression, suicide ideation, and plan among adults presenting with psychosis in psychiatric emergency care, Psychosis. Available on (https://www .tandfonline.co $\begin{array}{lll}\mathrm{m} / \text { doi/abs/10.1080/ } & 17522439 & 2021.191281\end{array}$ 5 ?needAccess $=$ true $\&$ journalCode $=$ rpsy20) accessed on july 2021 at 9 pm.

Cates, A., Catone, G., Marwaha, S., Bebbington, P., Humpston, C. \& Broome, M. (2021). Self-harm, suicidal ideation, and 
the positive symptoms of psychosis: Crosssectional and prospective data from a national household survey, Schizophrenia Research 233 (2021) 80-88

Dai, Q., Wang, D., Wang, J., Xu, H. \& Andriescue, E. (2021). Suicide attempts in Chinese Han patients with schizophrenia: cognitive, demographic, and clinical variables, Braz J Psychiatry, 43(1):29-34

Freeman, D., Bold, E., Chadwick, E., Taylor, K. M., Collett, N., Diamond, R., \& Waite, F. (2019). Suicidal ideation and behaviour in patients with persecutory delusions: Prevalence, symptom associations, and psychological correlates, Comprehensive Psychiatry, Volume 93, August 2019, 41-47

Eed, Z. \& El-Sayed, S. (2018). Nurse's Awareness of the Relationship be- tween Suicidal Ideation and Schizophrenic Patient's Positive/Negative Symptoms. Volume 9, Issue 1,Page 171-186 PDF (501.19 K)

El Monsheda, A. , \& Amr, M. (2020). Association between perceived social part and recovery among patients with schizophrenia . International Journal Africa Nursing Sciences . 13 , ( 2 ) , pp 236-242

Fekih-Romdhane, F., Amri, A. \& Cheour, M. (2021). Suicidal ideation, suicide literacy and stigma, disclosure expectations and attitudes toward help-seeking among university students: The impact of schizotypal personality traits, Wiliy Journal, Early Intervention in Psychiatry. 20(2);1- 11.

Filipcic , I. , Ivezić , E. , Jaksic , N. , Mayer , N. , Grah , M. , Kurman , M. , Herceg \& Filipcic , I. ( 2020 ) : Gender differences in early onset of chronic played multimorbidities in schizophrenia spectrum disorder. De women suffer Early Intervention in Psychiatry , 14 , pp 418-427 .

Hassan, A., Luca, V., Asmundo, A., Nunno, N., Monda, M. \& Villano, I. (2021):Effectiveness of Antipsychotics in Reducing
Suicidal Ideation: Possible Physiologic Mechanisms. Healthcare 2021, 9, 389

Holm, M. , Taipale , H. , Tanskanen , A. Tiihonen , J. , \& Mitterdorfer - Rut . E ( 2020). Employment among people with schizophrenia or bipolar disorder . A population - based study using nationwide registers . Acta Psychiatrica Scandinavica . 143 , ( 1 ), pp 61-71.

https://infocenter.nimh.nih.gov/pubstat ic/21MH-6389/21-MH-6389.pdf.

https://infocenter.nimh.nih.gov/pubstat ic/21MH-6389/21-MH-6389.pdf.

Ibrahim , S. , \& Ahmed , F. ( 2019 ). Effect of the nursing practice of creative art therapy on psychiatric symptoms among schizophrenic patients . American Journal of Nursing Research . 7 , ( 1 ), pp 14-23.

Jahn, D., Bennett., M. \& Park, S. (2016). The interactive effects of negative symptoms and social role functioning on suicide ideation in individuals with schizophrenia, Schizophrenia Research 170 (2016) 271-277 Javitt D. (2019). "Balancing therapeutic safety and efficacy to improve clinical and economic outcomes in schizophrenia: a clinical overview". The American Journal of Managed Care. 20 (8 Suppl): S1605. PMID 25180705.

Kiwan, N., Mahfoud, Z., Ghuloum, S., Yehya, A. \& Hammoudeh, S. (2020). SelfReported Sleep and Exercise Patterns in Patients with Schizophrenia: a CrossSectional Comparative Study, International Journal of Behavioral Medicine (2020) 27:366-377

Laura A., Tuula I., Tuula K., Jaana S., Maija L.(2021). Mental Imagery in Early Psychosis

https://journals.sagepub.com/doi/full/10.1177/ 02762366211021762

Leo S. \& René S. (2019). Suicide in Schizophrenia: An Educational 
Overviewhttps://www.ncbi.nlm.nih.gov/pmc/ articles/PMC6681260/

Luo , Y. , Pang, L., Zhao , Y. , Guo , C. , Zhang, L. , \& Zheng, X. ( 2020 ). Gender difference in the association between education and schizophrenia in Chinese adult . BMC Psychiatry . 20 , ( 296 ), pp 366-374. Pilot

Manea , A. , Zaki , R. , \& Morsi , A. (2020). The relationship between insight and quality of life among schizophrenic patients. Egyptian Joumal of Health Care . 11, ( 4 ), pp 212-224

McNamara, B., Same, A. \& Rosenwax, L. (2018). Palliative care for people with schizophrenia: a qualitative study of an underserviced group in need, BMC Palliative Care (2018) 17:53

Mikhael, V., El-Sayed, H., El-Bakry, S. \& Dawoud, B. (2020):- Evaluation of Suicide Risk in Chronic Schizophrenic Hospitalized Patients, Benha Journal of Applied Sciences (BJAS) print : ISSN 2356-9751 Vol.(5) Issue(5) Part (1) (2020), (21-28)

Mondal, A. \& Kumar, M. (2021):Rorschach inkblot test and psychopathology among patients suffering from schizophrenia: A correlational study, Ind Psychiatry J 2021; 30:74-83

$\begin{array}{lcr}\text { National } & \text { Institute of } & \text { Mental Health } \\ \text { (NIMH) } & (\mathbf{2 0 2 0}): & \text { Schizophrenia }\end{array}$ www.nimh.nih.gov. accessed at. 11/7/2021at 5PM.

National Institute of Mental Health (NIMH) (2021): Frequently Asked Questions about Suicide.

Owen M., Sawa A., Mortensen B. (2016): "Schizophrenia"

. Lancet. 388 (10039): 86-

97. doi:10.1016/S0140-6736(15)01121-

6. PMC 4940219. PMID 26777917.

Paschall, S. (2021) :- Positive Symptoms of Schizophrenia and Suicide: A Systematic Review of Gender, Race/Ethnicity, and
Premorbid IQ Variables, public e Doctorate of Psychology degree with a major in Clinical Psychology, Florida School of Professional Psychology at National Louis University available

on

(https://digitalcommons.nl.edu/cgi/viewconte nt.cgi article $=1608 \&$ context $=$ diss $) \quad$ accessed on july 2021 at $9 \mathrm{pm}$.

Pinho, L. G. D., Pereira, A., \& Chaves, C. (2020). Nursing interven- tions in schizophrenia: The importance of therapeutic relationship. Nursing and Care Open Access Journal, 3(6), 331- 333.PMID 26777917.Psychiatric and Mental HealthNurs- ing1, 2, Faculty of Nursing, Suez Ca- nal University

Sánchez-Sansegundo, M., Portilla-Tamarit, I., Rubio-Aparicio, M., AlbaladejoBlazquez, N. \& Ruiz-Robledillo, N. (2020):Neurocognitive Functioning and Suicidal Behavior in Violent Offenders with Schizophrenia Spectrum Disorders, Diagnostics 2020, 10, 1091

Setiawati , M. , \& Suaryan , L. ( 2020 ) : Differences in socio - demographie characteristics of schizophrenia patients between rural and urban Areas in Badung Regency . Warmadewa Medical Journal . 5 , ( 2 ), pp 76-84 .

Shalanda A., Youssef A., Mahdy R., \& Zayed A. ( 2019 ) : The relationship between childhood trauma and schizophrenia symptoms severity at Zagazig University Hospitals . The Egyptian Journal of Hospital Medicine . 77 , ( 3 ), pp 5114-5120

Stip, E., Caron, J., Tousignant, M. \& Lecomte, Y. (2017):- Suicidal Ideation and Schizophrenia: Contribution of Appraisal, Stigmatization, and Cognition, The Canadian Journal of Psychiatry / La Revue Canadienne de Psychiatrie, Vol. 62 (10) 726 -734

Tyrer P ,Freeman C \& Methuen C. (2006). Rating Scales in Psychiatry. Jn Research Methods in Psychiatry. 3rd ed. Royal College 
of Psychiatrists, London, (JK.

Ventriglio, A., Gentile, A., Bonfitto, I., Stella, E., Mari, M., Steardo, L. \& Bellomo, A. (2016). Suicide in the Early Stage of Schizophrenia, Front Psychiatry. 2016; 7: 116.

Willacy, H. (2020). Experiences of Medication Adherence Among People with Schizophrenia: A Qualitative Sys- tematic American Journal of Nursing Research, 2019, Vol. 7, No. 4, 589-597 Available onlineat http://pubs.sciepub.com/ajnr/7/4/21 Published by Science and Education PublishingDOI:10.12691/ajnr-7-4 -21

World Health Organization (WHO) (2021). Guidance to help the world reach the target of reducing suicide rate by 2030 .

Yazici, E., Cimen, Z., Akyollu, I., Yazici, A., Turkmen, B. \& Erol, A. (2018). Depressive Temperament in Relatives of Patients with Schizophrenia Is Associated with Suicidality in Patients with Schizophrenia Clinical Psychopharmacology and Neuroscience;16(3):302-30

Yttri J., Urfer - Parnas, A., \& Parnas , J. (2020). Auditory Verbal Hallucinations in Schizophrenia, Mode of onset and disclosure. Journal of Nervous and Mental Disease , 208 , ( 9 ) , pp 689-693. 


\section{العلاقة بين الأفكار الانتحارية والأعراض الإيجابية لاى مرضى الفصام \\ بسمه السيد احمد محمد- معالي ابر اهيم المالكي- مو اهب محمود زكي}

الفصام هو اضطر اب عقلي تتخلل آثاره جميع جوانب الأداء النفسي والاجتماعي ويرتبط بالوفاة المبكرة وتؤثر الأعر اض الإيجابية مثل الهلوسة و الأوهام على خطر الانتحار بين الأفر اد الذين تم تشخيص إصسابتهم بالفصام. لذا هدفت هذه الدراسة الي تقييم العلاقة بين الأفكار الانتحارية والأعر اض الإيجابية لدى مرضى الفصام. وقد أجريت هذه الدر اسة بمستشفى الامر اض النفسيه و العقلية على ، . 1 مريض مصاب بالفصام ـ ولخصت الدر اسة بوجود علاقة ارتباط ذات دلالة إحصائية بين المقياس الكلي لتقييم الأعراض الإيجابية والفكر الانتحاري الكلي. كما اوصت الدراسة بتطوير التدخلات النفسية ، و تقليل التدخلات الأسرية من مخاطر السلوك الانتحاري ، ومن الضروري إجراء مزيد من الدر اسات باستخدام عينة احتمالية كبيرة لتعميم النتائج. 